\title{
Treatment of locally advanced cervical cancer in a patient with a bicornuate uterus with MRI-guided intracavitary/interstitial brachytherapy
}

\author{
Denise Fabian, MD', Allison LaRocco, BS², Meghan Olsen, MD', Allison Quick, MD' \\ 'Department of Radiation Oncology, The Ohio State University Comprehensive Cancer Center - Arthur G. James Cancer Hospital and Richard \\ J. Solove Research Institute, Columbus, OH, Unites States, ${ }^{2 T h e}$ Ohio State University College of Medicine, Columbus, OH, United States
}

\begin{abstract}
Purpose: Definitive treatment for locally advanced cervical cancer (LACC) includes external beam radiation therapy (EBRT) with concurrent cisplatin and brachytherapy. Image-guided intracavitary brachytherapy utilizes CT and/or MRI for target and organ at risk delineation and has been shown to improve local control rates and decrease toxicity. Hybrid intracavitary/interstitial applicators can be used to improve tumor coverage in certain cases. We describe the use of combined intracavitary/interstitial brachytherapy to treat a cervical cancer patient with a bicornuate uterus.

Case presentation: A 30-year-old female with bicornuate uterus and FIGO IB2 adenocarcinoma of the cervix was treated with 45 Gy of EBRT to the pelvis with concurrent weekly cisplatin. An examination after EBRT demonstrated a persistent bulky tumor covering most of the cervix. Brachytherapy was delivered via a combined intracavitary/ interstitial approach, using a tandem and ring applicator and an interstitial needle. The placement of the tandem was alternated between uterine cornua with each fraction, and the interstitial needle was placed on the side opposite the tandem. CT and MRI were obtained with each fraction. The patient completed the treatment without complications. Three-month restaging PET-CT showed significant interval improvement in the cervix, with a complete clinical response on physical examination. The patient is without evidence of disease 18 months after the treatment.

Conclusions: We found that the use of the hybrid applicator allowed for adequate target coverage in a patient with unusual anatomy. The patient tolerated treatment well and demonstrated favorable response on follow-up exam and imaging. The long-term curative result needs to be further evaluated.

Key words: cervical cancer, brachytherapy, bicornuate uterus, image guided, hybrid applicator, MRI.

\begin{abstract}
Purpose
Cervical cancer is the fourth most common cancer in women worldwide with 570,000 new cases diagnosed in 2018 , and is the third leading cause of cancer-related deaths in women in developing countries [1]. In patients with locally advanced cervical cancer (LACC), the ultimate treatment includes external beam radiation therapy (EBRT) with concurrent cisplatin and a brachytherapy boost $[2,3,4]$. Brachytherapy improves survival compared to EBRT alone [5], but it is also associated with treatment-related toxicity [6]. The use of three-dimensional (3D) image-guided brachytherapy (IGBT) allows for conformal dose escalation to the tumor while reducing dose to organs at risk (OARs). IGBT utilizes computed tomography (CT) and/or magnetic resonance imaging (MRI)based imaging for target and OARs delineation, and has been shown to improve local control rates and decrease
\end{abstract}

toxicity compared to two-dimensional (2D) treatment planning [7].

Brachytherapy for cervical cancer can be done with an intracavitary, interstitial, or combined approach [8]. Intracavitary brachytherapy, utilizing tandem and ring or ovoids, is the most common approach [9]. Interstitial brachytherapy can be used when intracavitary brachytherapy is not sufficient for tumor coverage or appropriate for the patient's anatomy. Indications for interstitial brachytherapy include large residual tumor after EBRT, distal vaginal involvement, or vaginal stenosis resulting in poor applicator fitting [10]. Hybrid implants allow interstitial needles to be placed in combination with intracavitary applicators [11].

Uterine anomalies are present in about $5.5 \%$ of the female population [12]. Brachytherapy requires applicator placement specific to the patient's anatomy to deliver the prescribed dose to the cervix and uterus, making the 
treatment of women with morphological anomalies of the reproductive tract challenging. In this paper, we describe the applicator placement technique, imaging, treatment planning, and patient management of a female with locally advanced cervical cancer and a bicornuate uterus who received hybrid intracavitary/interstitial brachytherapy.

\section{Clinical scenario}

A 30-year-old BRCA1 mutation-positive woman with a bicornuate uterus presented to an outside institution with 3 months of vaginal pain and heavy vaginal bleeding. Ultrasound at the time revealed a potential cyst on the cervix. Two months later, a transvaginal ultrasound revealed a cervical mass measuring $1.8 \times 3.1 \times 1.6 \mathrm{~cm}$. Pelvic exam demonstrated a $3 \times 4 \mathrm{~cm}$ fungating cervical mass without vaginal or parametrial extension. A cervical biopsy was positive for poorly differentiated invasive adenocarcinoma, and the patient was clinically staged with FIGO stage IB2 cervical adenocarcinoma. MRI showed a bicornuate uterus and a $3.5 \mathrm{~cm}$ mass involving the cervix, with a mass invading the upper left vagina and an irregular margin along the adjacent left parametria. Positron emission tomography (PET)-CT showed a hypermetabolic cervical mass, but no abnormal lymphadenopathy or distant disease. Radical hysterectomy with lymph node dissection was planned. However, intraoperative pathology from a pelvic lymph node frozen section was positive for carcinoma, and the hysterectomy was subsequently aborted. The bilateral pelvic and para-aortic lymph node dissection was completed, and the patient also underwent prophylactic bilateral salpingo-oophorectomy due to BRCA1 mutation-positive status. On final pathology, one out of eight pelvic lymph nodes were positive for metastatic disease; all para-aortic lymph nodes were negative.

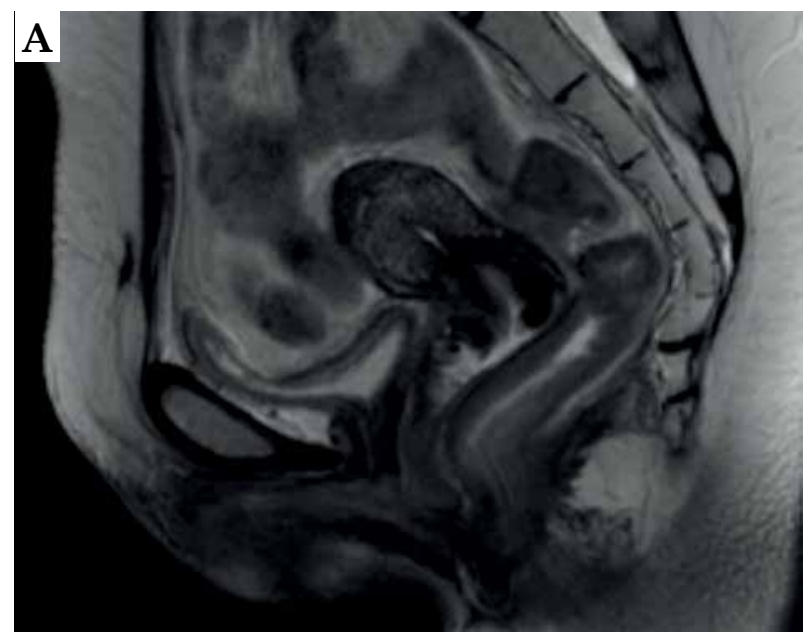

Approximately one month after the surgery, the patient presented to our institution. Physical exam revealed a $6 \mathrm{~cm}$ bulky tumor of the cervix involving the left vaginal fornix, but no obvious parametrial invasion. She was treated with 3D conformal pelvic EBRT, 45 Gy in 25 fractions with concurrent weekly cisplatin $\left(40 \mathrm{mg} / \mathrm{m}^{2}\right)$.

\section{Technique for brachytherapy}

\section{Preparation}

Prior to the first brachytherapy treatment, another physical exam and pelvic MRI were completed to determine response to EBRT and to evaluate the extent of residual disease. The exam of our patient at that time showed persistent exophytic, friable tumor on the cervix and left vaginal fornix. MRI of the pelvis demonstrated a bicornuate uterus and a fullness in the cervix with enhancement of the parametrial tissues and a defect in the left anterior vaginal fornix with T2 hyperintensity (Figure 1). Due to the imaging findings concerning residual parametrial involvement and challenging uterine anatomy, we opted to use a combined intracavitary/interstitial approach using the Varian 3D interstitial ring applicator set (Varian Medical Systems, Palo Alto, California, USA). Pre-procedural evaluation included complete blood count to ensure adequate platelet count and absence of neutropenia, and assessment of anesthesia risks based on her other medical comorbidities.

\section{Procedure}

On the first day of brachytherapy treatment, the patient underwent conscious sedation for applicator placement. Once sedated, she was placed in the dorsal lithotomy position. An exam under anesthesia showed residual friable disease in the cervix, predominately in the left aspect of

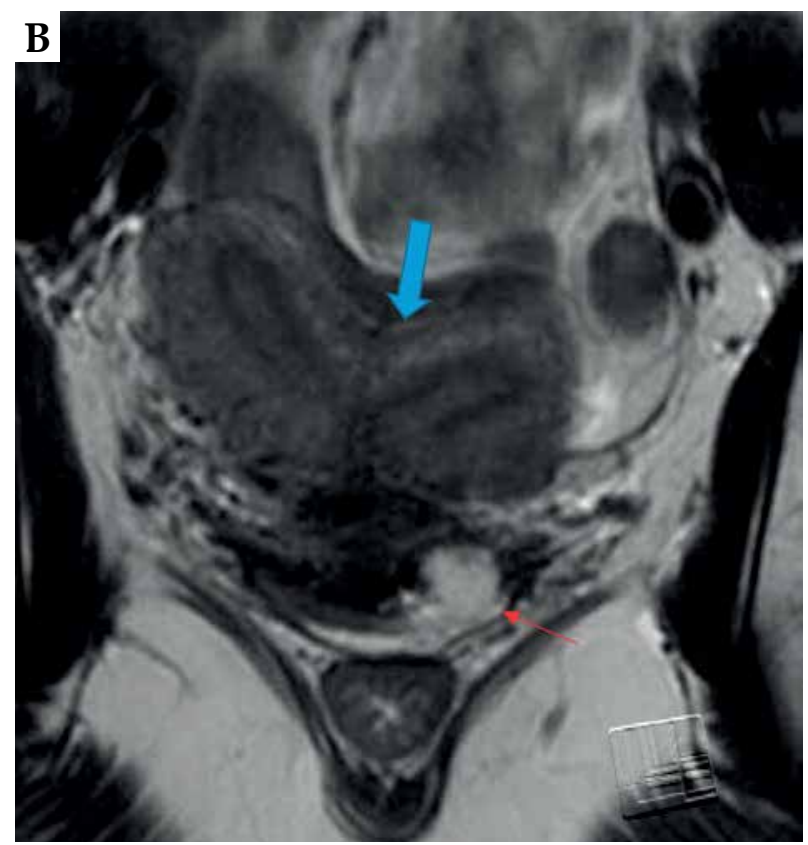

Fig. 1. T2 sagittal (A) and coronal (B) MRI at diagnosis showing mass in cervix and left vagina (red arrow) and bicornuate uterus (blue arrow) 
the cervix and left vaginal fornix. She was then prepped and draped for the procedure. A Foley was placed with $7 \mathrm{~mm}$ dilute omnipaque in the bulb and $120 \mathrm{cc}$ of saline was injected into the bladder to improve the visualization of uterine anatomy during transabdominal ultrasound imaging. Next, a speculum exam was performed, and the uterus was sounded to $6 \mathrm{~cm}$. The cervix was dilated to a size \#18. After the cervix was fully dilated, a 60-degree $6 \mathrm{~cm}$ plastic tandem was placed into the uterus in the right cornua under ultrasound guidance to reduce the risk of uterine perforation. The ring was then placed and secured. The interstitial needle was inserted into the left parametria using the 3:00 position of the ring to a depth of $3 \mathrm{~cm}$ (Figure 2A, B). The depth of needle placement was determined based on the estimated extent of parametrial involvement superior to the cervical os on MRI. The needle was marked at that predetermined depth, with an extra centimeter added to account for the thickness of the ring. The needle was then externally secured to the ring and tandem. The vagina was packed with gauze to displace rectum and bladder, and to stabilize the applicators. The Foley was unclamped, allowing the bladder to empty. A CT was performed to verify applicator placement, and to determine if the position of the needle required superior or inferior adjustment within the patient or a lateral adjustment by utilizing a different hole of the ring. CT was also used to verify that the needles were not placed into the bladder, rectum, or bowel. Following CT, axial T2, sagittal T2, and axial LAVA MRI images were obtained and fused with the CT images in Eclipse image registration for treatment planning. Delineation of the high-risk clinical target volume (HRCTV) and OARs was done on the axial T2 sequences, which were fused to the planning CT (Figure 2C, D). BrachyVision (Varian Medical Systems, Palo Alto, California, USA) was used to manually optimize the treatment plan to cover the HRCTV with the prescription dose of 5.5 Gy per fraction. Twelve dwell positions of the tandem were loaded, with a gradual taper of dwell time duration from the tip of the tandem to position at the level of the ring. Fourteen of eighteen dwell positions of the ring were loaded for the treatment (the four positions along the posterior aspect of the ring near the rectum were not used). Six dwell positions of the needle were utilized, and approximately $9 \%$ of the
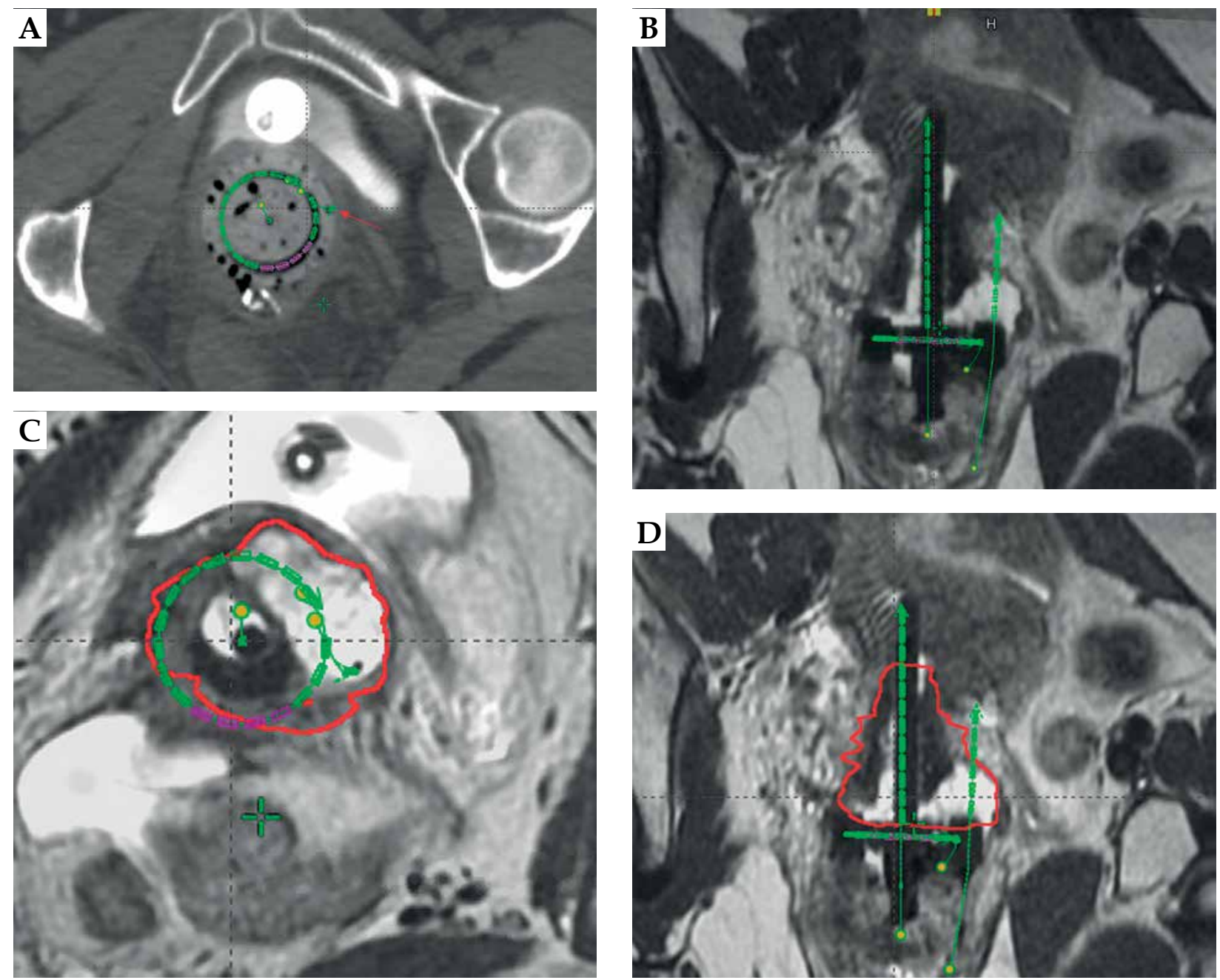

Fig. 2. A) Axial CT with needle at the 3:00 position of the ring (red arrow); B) Coronal CT with tandem in right cornua and needle in left parametria; C) HRCTV contoured on axial T2 MRI fused with planning CT; D) HRCTV on coronal T2 MRI fused with planning CT 
treatment dose was delivered through the needle. After the plan was generated, it was reviewed and approved by the physician based on a HRCTV $\mathrm{D}_{90}$ (the minimum dose covering $90 \%$ of the volume) of at least $90 \%$, with acceptable dose of $2 \mathrm{cc}$ (D2 cc) of the bladder, rectum, and sigmoid. Dose to the HRCTV and OARs was tracked and documented on a spreadsheet provided by the ABS (https:/ / www.americanbrachytherapy.org/guidelines/ brachytherapy-guidelines-and-consensus-statements/). Treatment was delivered via GammaMed high-dose-rate (HDR) remote afterloader (Varian Medical Systems, Palo Alto, California, USA).

For our patient, the placement of the tandem was alternated between uterine cornua with each fraction, and the interstitial needle was placed on the side opposite the tandem to optimize coverage of the HRCTV. For fractions 2 and 4, the tandem was placed in the left cornua and

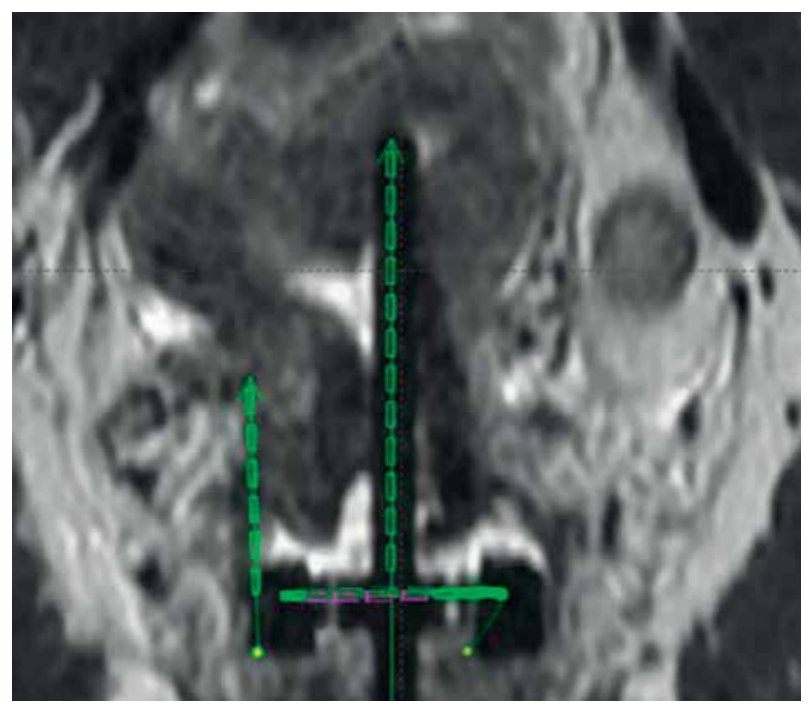

Fig. 3. Coronal CT with tandem in left cornua and needle in right parametria for fractions 2 and 4 the needle was positioned in the right parametria using the 9:00 position of the ring (Figure 3 ). The $3^{\text {rd }}$ and $5^{\text {th }}$ fractions were identical to the first fraction where the tandem was placed in the right cornua and the needle was placed in the left parametria. The dose distribution from the applicator placement is shown in Figure 4. The needle length and depth and the tandem angle were consistent across all 5 fractions. Due to excellent coverage of the HRCTV, the prescription dose was lowered to $4.5 \mathrm{~Gy}$ for the final fraction.

The patient's total brachytherapy dose was $26.5 \mathrm{~Gy}$ in 5 fractions, delivered on non-consecutive days. Combined with dose from EBRT, the total $\mathrm{EQD}_{2}$ dose to the HRCTV was $90 \mathrm{~Gy}$, and D2 cc of the bladder, rectum, and sigmoid were 75.8 Gy, 59.1 Gy, and 65.6 Gy, respectively. The patient tolerated the treatment well and had no unexpected acute treatment-related toxicity.

\section{Patient management}

Conscious sedation was used for placement of applicators for each fraction to ensure patient's comfort and to minimize body movement during needle placement. Once the applicators were placed and imaging confirmed that no additional adjustments were required, the sedation was discontinued, and the pain was managed through IV medications as needed during the time dedicated to treatment planning and prior to applicator removal. After treatment was completed, the packing, interstitial needle, ring, and tandem were removed. The patient was assessed for heavy vaginal bleeding prior to discharge from the facility and counseled on anticipated short-term effects. She was provided with prescriptions for supportive medications as indicated.

\section{Follow-up}

Our patient was seen one month after the treatment, at which time she had a significant improvement in the cervical mass, with some necrosis versus residual disease
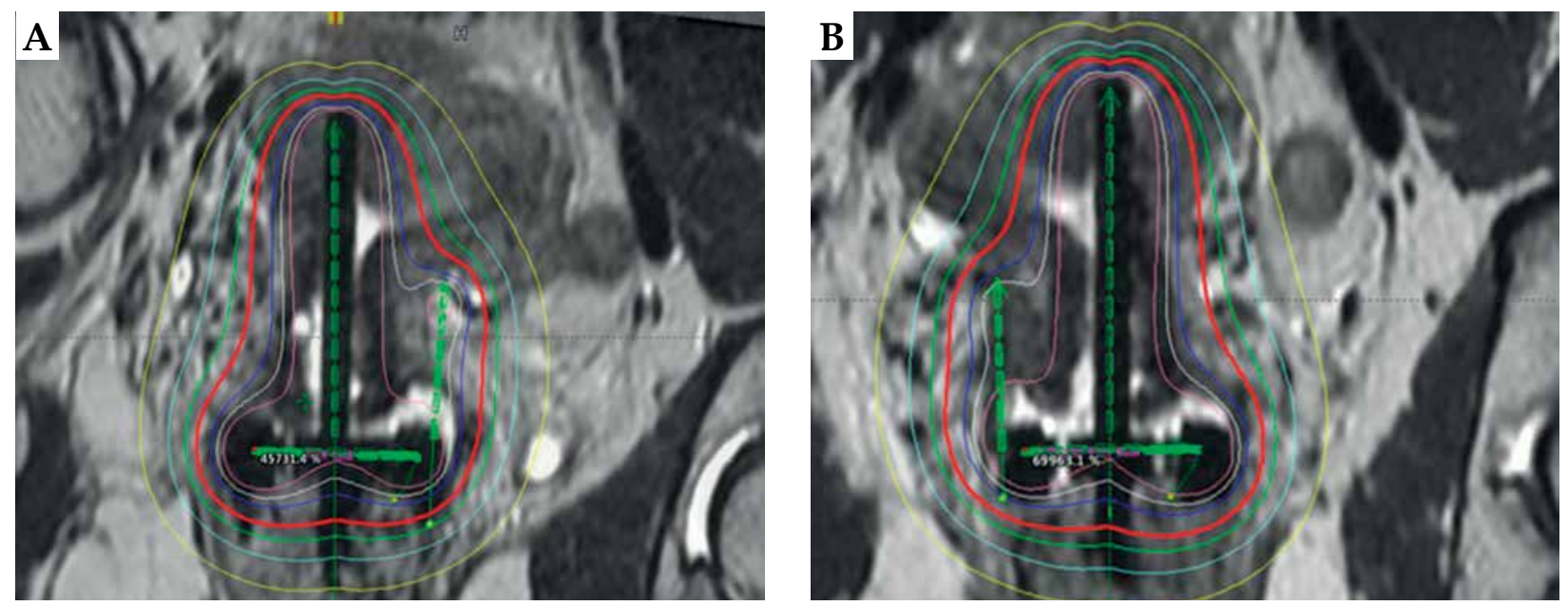

Fig. 4. A) MRI with dose distribution illustrating alternation of the tandem and needle location between the dose fractions with the dose distribution included. Panel A illustrates the needle in the left parametria; B) MRI with dose distribution illustrating alternation of the tandem and needle location between the dose fractions with the dose distribution included. Panel B illustrates the needle in the right parametria 
in the cervix and left vaginal fornix. She was followed closely for resolution of these findings. Three-month restaging PET-CT showed a significant improvement and she ultimately had a complete clinical response on physical examination. At 18 months after the treatment, the patient is without an evidence of the disease. Unfortunately, the patient developed grade 2 vaginal atrophy and grade 3 mixed urinary incontinence that has not improved with conservative management. She is now planning to have a sacral nerve neurostimulator placed to manage her urinary symptoms.

\section{Discussion}

Cervical cancer is one of the most common cancers to affect women worldwide and has the $14^{\text {th }}$ highest incidence of all cancers in the United States (US) [13], with 13,170 estimated new cases of cervical cancer diagnosed every year [14]. Around $45 \%$ of women will be diagnosed with localized disease and have a $92 \%$ of five-year survival prognosis [14]. Unfortunately, 35\% will have regional disease and $15 \%$ will have distant disease at diagnosis and subsequently, have lower five-year survival rates (56\% and $17 \%$, respectively) [14].

Locally advanced cervical cancer is treated with a combination of EBRT with concurrent cisplatin and brachytherapy. The addition of brachytherapy to EBRT improves cervical cancer outcomes [15], including local control and overall survival (OS) [16]. In a review of 983 patients with FIGO stage IIIB, in cervical cancer patients treated with EBRT and brachytherapy verses EBRT alone, the disease-specific 5-year survival rate was better in patients who received combination treatment compared to those treated with EBRT alone ( $45 \%$ vs. $24 \%, p<0.0001)$. Furthermore, patients treated with brachytherapy also had a lower pelvic disease recurrence and lower complications at 5 years [17]. Outcomes with definitive chemoradiation have continued to improve with 3D IGBT (see Table 1).

Precise brachytherapy applicator placement is vital to successful treatment [10], and the anatomy of structural uterine anomalies could pose a challenge to accurately deliver the dose using a standard intracavitary approach. In an analysis of patients enrolled in prospective RTOG clinical trials for LACC (RTOG 0116 and 0128), the quality of brachytherapy placement was found to impact recurrence rates [5]. Patients with unacceptable applicator placement had an increased risk of local recurrence (HR $=2.5, p=0.03)$ and lower disease-free survival $(\mathrm{HR}=2.06$, $p=0.03$ ) [5]. The effect of a bicornuate uterus on applicator placement is not known; however, like 3D IGBT with $\mathrm{CT}$ and MRI for intact cervix cancer with normal uterine anatomy, we were able to confirm applicator placement and provide adequate dose to the HRCTV with acceptable dose to the OARs [18].

A literature search revealed approximately eight other case reports $[19,20,21,22,23,24,25,26]$ of women with cervical cancer and Mullerian duct anomalies who were treated with brachytherapy. Due to lack of spe- cific guidelines regarding brachytherapy treatments in patients with uterine anomalies, several different intracavitary techniques have been used, including tandems and ovoids, tandem and cylinders, and a customized vaginal mold $[20,22,23,25,26]$. A recent case was reported on a 61-year-old female with FIGO IIB SCC of the cervix with uterine didelphys and a double vagina who was treated with EBRT to the pelvis to 50 Gy in 25 fractions. She then received 4 HDR tandem and ovoid brachytherapy treatments, with the tandem placed in the left uterus for three treatments and in the right uterus for one treatment. The ovoids were placed in the left vagina once, and then in the vaginal bilaterally for the final three treatments. Treatment was planned 2 dimensionally with point doses and orthogonal imaging. The patient achieved a complete clinical response to treatment [24]. Our report is unique because the challenging anatomy of a bicornuate uterus in our patient was successfully overcome by using a hybrid applicator. The tandem and interstitial needle were alternated between the cornua and opposite parametria with each treatment. This allowed for excellent coverage of the target with a HRCTV dose of 90 Gy that has resulted in durable local control 18 months after the treatment completion. In addition, the dose to the OARs was acceptable; even though, unfortunately, the patient developed late grade 3 urinary incontinence.

MRI-based image-guided adaptive brachytherapy (IGABT) and the increased use of hybrid intracavitary/ interstitial brachytherapy is expected to improve outcomes for cervical cancer beyond that achieved with 2D or CT-guided brachytherapy. Data from the retrospective RetroEMBRACE study showed that MRI-based IGABT resulted in excellent local control (91\%) and overall survival $(74 \%)$ at 3 years with limited severe toxicities [27]. A new clinical outcome was 'benchmarked' for patients treated with MRI-based IGABT in the prospective EMBRACE trial [28]. The EMBRACE II study, which is currently open and enrolling participants, utilizes MRI IGABT with hybrid applicators to continue to improve local control and survival, and decrease treatment-related toxicity for women with LACC [29].

\section{Conclusions}

Brachytherapy for women with cervical cancer with a bicornuate uterus can be challenging, since the anatomic anomaly is not encountered frequently. With appropriate imaging modalities, including the use of ultrasound during placement of the applicators and CT and MRI for treatment planning, the IGRT hybrid intracavitary/ interstitial brachytherapy can be done and can achieve excellent tumor coverage with acceptable dose to normal tissue. Our patient tolerated the treatment well and achieved durable clinical response.

\section{Disclosure}

Authors report no conflict of interest. 
Table 1. Table of 3D brachytherapy outcomes studies

\begin{tabular}{|c|c|c|c|c|c|c|c|c|}
\hline Study & Imaging & $\begin{array}{c}\text { EBRT } \\
\text { technique }\end{array}$ & $\begin{array}{c}\text { Brachytherapy } \\
\text { technique }\end{array}$ & Dose & $\begin{array}{l}\text { Fol- } \\
\text { low-up }\end{array}$ & $N$ & $\begin{array}{l}\text { Local } \\
\text { relapse-free } \\
\text { survival }\end{array}$ & Survival \\
\hline $\begin{array}{l}\text { Charra- } \\
\text { Brunaud } \\
\text { et al., } 2012 \\
{[30]}\end{array}$ & $\begin{array}{c}\text { Orthogonal } \\
\text { X rays vs. } \\
\text { CT }\end{array}$ & $2 \mathrm{D}$ and $3 \mathrm{D}$ & $\begin{array}{l}\text { LDR or PDR in 2D } \\
\text { arm; PDR BT in } \\
\text { 3D arm; applica- } \\
\text { tor varied }\end{array}$ & Variable & $2 \mathrm{yrs}$ & $\begin{array}{l}\text { 2D: } 336 \\
\text { 3D: } 369\end{array}$ & $\begin{array}{c}\text { 2D: 73.9- } \\
\text { 91.9\%; } \\
\text { 3D: } 78.5- \\
100 \%\end{array}$ & \\
\hline $\begin{array}{l}\text { Gill et al., } \\
2015 \text { [31] }\end{array}$ & MRI & $3 D$ & $\begin{array}{l}\text { Intracavitary } \\
\text { BT using ring } \\
\text { and tandem } \\
\text { technique }\end{array}$ & $\begin{array}{c}25-30 \text { Gy in } \\
5 \mathrm{fx}\end{array}$ & $2 \mathrm{yrs}$ & 128 & $91.6 \%$ & OS: $81.8 \%$ \\
\hline $\begin{array}{l}\text { Haie-Meder } \\
\text { et al., } 2009 \\
\text { [32] }\end{array}$ & MRI & $3 \mathrm{D}$ & $\begin{array}{c}\text { Intracavitary LDR } \\
\text { BT with vaginal } \\
\text { mold }\end{array}$ & $\begin{array}{c}79 \text { Gy } \\
\text { (median } \\
\text { HRCTV D }_{90} \text { ) }\end{array}$ & $\begin{array}{c}2 \text { yrs (LC) } \\
3 \text { yrs } \\
(\mathrm{OS})\end{array}$ & 84 & $89.2 \%$ & $\begin{array}{l}\text { OS: } \\
67 \%\end{array}$ \\
\hline $\begin{array}{l}\text { Kang et al., } \\
2010 \text { [33] }\end{array}$ & $\mathrm{CT}$ & $2 D$ and $3 D$ & $\begin{array}{l}\text { HDR intracav- } \\
\text { itary BT, intra- } \\
\text { uterine tandem } \\
\text { and ovoid pair }\end{array}$ & Variable & $\begin{array}{l}\text { 2D: } \\
4.7 \mathrm{yrs} \\
3 \mathrm{D}: \\
3.4 \mathrm{yrs}\end{array}$ & $\begin{array}{l}\text { 2D: } 133 \\
\text { 3D: } 97\end{array}$ & $\begin{array}{l}\text { 2D: } 91 \% \\
\text { 3D: } 97 \%\end{array}$ & $\begin{array}{c}\text { PFS: } \\
\text { 2D: } 80 \% \\
\text { 3D: } 80 \%\end{array}$ \\
\hline $\begin{array}{l}\text { Lindegaard } \\
\text { et al., } 2013 \\
\text { [34] }\end{array}$ & MRI & $3 \mathrm{D}$ & $\begin{array}{l}\text { PDR BT with ba- } \\
\text { sic tandem-ring } \\
\text { plastic IC appli- } \\
\text { cator, IGABT }\end{array}$ & $\begin{array}{c}85 \text { Gy } \\
(\text { HRCTV } \\
\left.D_{90}\right)\end{array}$ & 3 yrs & 140 & $91 \%$ & $\begin{array}{l}\text { OS: } \\
79 \%\end{array}$ \\
\hline $\begin{array}{l}\text { Narayan } \\
\text { et al., } 2009 \\
\text { [35] }\end{array}$ & MRI & $3 D$ & $\begin{array}{l}\text { LDR or confor- } \\
\text { mal HDR BT; } \\
\text { tandem and } \\
\text { ovoid or vaginal } \\
\text { cylinder }\end{array}$ & $\begin{array}{c}\text { HDRc: } \\
\text { 28-30 Gy in } \\
\text { 4-5 fx } \\
\text { LDR: } \\
\text { 40-45 Gy in } \\
\text { 2 fx }\end{array}$ & 5 yrs & 217 & & $\begin{array}{l}\text { OS: } \\
60 \%\end{array}$ \\
\hline $\begin{array}{l}\text { Pötter et al., } \\
2011 \text { [36] }\end{array}$ & MRI & $3 \mathrm{D}$ & $\begin{array}{l}\text { HDR intracavi- } \\
\text { tary or intracav- } \\
\text { itary/interstitial } \\
\text { with Vienna ring } \\
\text { applicator }\end{array}$ & $\begin{array}{c}\text { HDR: } \\
4 \times 7 \text { Gy }\end{array}$ & $3 \mathrm{yrs}$ & 143 & $95 \%$ & $\begin{array}{l}\text { OS: } \\
68 \%\end{array}$ \\
\hline $\begin{array}{l}\text { Rijkmans } \\
\text { et al., } 2014 \\
{[37]}\end{array}$ & MRI & $2 \mathrm{D}$ and $3 \mathrm{D}$ & $\begin{array}{l}\text { LDR \& HDR; } \\
\text { Intracavitary } \\
\text { tandem and } \\
\text { ovoids, occa- } \\
\text { sional use of } \\
\text { cylinder }\end{array}$ & Variable & 3 yrs & $\begin{array}{l}\text { CBT: } 43 \\
\text { IGRT: } 83\end{array}$ & $\begin{array}{c}\text { CBT: } \\
68 \% \\
\text { IGRT: } 93 \%\end{array}$ & $\begin{array}{c}\text { OS: } \\
\text { CBT: } 51 \% \\
\text { IGRT: } 86 \%\end{array}$ \\
\hline $\begin{array}{l}\text { Tan et al., } \\
2009 \text { [38] }\end{array}$ & CT & $3 \mathrm{D}$ & $\begin{array}{c}\text { Combined } \\
\text { intracavitary and } \\
\text { interstitial, using } \\
\text { Utrecht intracav- } \\
\text { itary applicator } \\
\text { and interstitial } \\
\text { needle }\end{array}$ & $\begin{array}{c}\text { HDR: } \\
21 \text { Gy in } \\
3 \text { fractions }\end{array}$ & 3 yrs & 28 & $96 \%$ & $\begin{array}{l}\text { CSS: } \\
81 \%\end{array}$ \\
\hline
\end{tabular}

$M R I$ - magnetic resonance imaging, CT - computed tomography, BT - brachytherapy, LDR-low-dose-rate, HDR-high-dose-rate, HDRC-high-dose-rate conformal, $P D R$ - pulsed-dose-rate, $f x$ - fractions, EBRT - external beam radiation therapy, yrs - years, CBT - conventional brachytherapy, IGRT - image-guided brachytherapy, CSS - cancer specific survival, HRCTV - high-risk clinical target volume, DFS - disease-free survival, OS - overall survival, IGABT-image-guided adaptive brachytherapy

\section{References}

1. Torre LA, Bray F, Siegel RL et al. Global cancer statistics, 2012. CA Cancer J Clin 2015; 65: 87-108.

2. NCCN Clinical Practice Guidelines in Oncology. Available at https://www.nccn.org/professionals/physician_gls/default.aspx. Accessed March 4, 2019.

3. Chemoradiotherapy for Cervical Cancer Meta-Analysis Collaboration. Reducing uncertainties about the effects of chemoradiotherapy for cervical cancer: a systematic review and meta-analysis of individual patient data from 18 randomized trials. J Clin Oncol 2008; 26: 5802-5812.

4. Eifel PJ, Winter K, Morris M et al. Pelvic irradiation with concurrent chemotherapy versus pelvic and para-aortic irradiation for high-risk cervical cancer: an update of Radiation Therapy Oncology Group trial (RTOG) 90-01. J Clin Oncol 2004; 22: 872-880. 
5. Viswanathan AN, Moughan J, Small W et al. The quality of cervical cancer brachytherapy implantation and the impact on local recurrence and disease-free survival in RTOG prospective trials 0116 and 0128. Int J Gynecol Cancer 2012; 22: 123-131.

6. Banerjee R, Kamrava M. Brachytherapy in the treatment of cervical cancer: a review. Int I Womens Health 2014; 6: 555-564.

7. Potter R, Kirisits C, Fidarova EF et al. Present status and future of high-precision image guided adaptive brachytherapy for cervix carcinoma. Acta Oncol 2008; 47: 1325-1336.

8. Nakano T, Kato S, Ohno T et al. Long-term results of highdose rate intracavitary brachytherapy for squamous cell carcinoma of the uterine cervix. Cancer 2005; 103: 92-101.

9. Viswanathan AN, Creutzberg CL, Craighead P et al. International brachytherapy practice patterns: a survey of the Gynecologic Cancer Intergroup (GCIG). Int J Radiat 2012; 82: 250-255.

10. Viswanathan AN, Thomadsen B; American Brachytherapy Society Cervical Cancer Recommendations Committee American Brachytherapy Society. American Brachytherapy Society consensus guidelines for locally advanced carcinoma of the cervix. Part I: general principles. Brachytherapy 2012; 11: 33-46.

11. Kirisits C, Lang S, Dimopoulos J et al. The Vienna applicator for combined intracavitary and interstitial brachytherapy of cervical cancer: Design, application, treatment planning, and dosimetric results. Int J Radiat Oncol Biol Phys 2006; 65: 624-630.

12. Chan YY, Jayaprakasan K, Zamora J et al. The prevalence of congenital uterine anomalies in unselected and high-risk populations: a systematic review. Hum Reprod Update 2011; 17: 761-771.

13. NIH Fact Sheets - Cervical Cancer. Available at https://report.nih.gov/nihfactsheets/viewfactsheet.aspx?csid=76. Accessed March 4, 2019.

14. Siegel RL, Miller KD, Jemal A. Cancer statistics, 2019. CA Cancer J Clin 2019; 69: 7-34.

15. Karlsson J, Dreifaldt AC, Mordhorst LB et al. Differences in outcome for cervical cancer patients treated with or without brachytherapy. Brachytherapy 2017; 16: 133-140.

16. Coia L, Won M, Lanciano R et al. The Patterns of Care Outcome Study for cancer of the uterine cervix. Results of the Second National Practice Survey. Cancer 1990; 66: 2451-2456.

17. Logsdon MD, Eifel PJ. FIGO IIIB squamous cell carcinoma of the cervix: an analysis of prognostic factors emphasizing the balance between external beam and intracavitary radiation therapy. Int J Radiat Oncol Biol Phys 1999; 43: 763-775.

18. Vargo JA, Beriwal S. Image-based brachytherapy for cervical cancer. World J Clin Oncol 2014; 5: 921-930.

19. Ishibashi N, Maebayashi $\mathrm{T}$, Aizawa $\mathrm{T}$ et al. Brachytherapy for cervical cancer in septate uterus: Dose-volume differences with tandem implant placement in right vs. left uterine canal: A case report. Oncol Lett 2018; 15: 7273-7278.

20. Loo HW, Locks SM. Squamous cell carcinoma of the cervix: report of an unusual case of bicornuate bicollis uterus treated with bilateral intracavity brachytherapy. Br J Radiol 2010; 83: e143-e146.

21. Platta CS, Wallace C, Gondi V et al. Cervical brachytherapy technique for locally advanced carcinoma of the cervix in a patient with septate uterus. J Contemp Brachytherapy 2014; 6: 76-81.

22. Yavas G, Yavas C, Inan G. Locally advanced squamous cell cervical cancer in a patient with septate uterus. J Contemp Brachytherapy 2017; 9: 487-489.

23. Gauwerky F. Double cervical carcinoma in a case of double uterus and subseptate vagina. Zentralbl Gynakol 1955; 77: 967-971.
24. Kaneyasu Y, Koh I, Fujiwara H et al. Concurrent chemoradiotherapy for locally advanced squamous cell carcinoma of the cervix in a uterus didelphys with vaginal septum. J Contemp Brachytherapy 2019; 11: 180-188.

25. Cordoba A, Escande A, Comte P et al. Locally advanced adenocarcinoma of the cervix on uterus didelphys: a case report. I Contemp Brachytherapy 2017; 9: 71-76.

26. Lee $C D$, Churn $M$, Haddad $N$ et al. Bilateral radical radiotherapy in a patient with uterus didelphys. Br J Radiol 2000; 73: 553-556.

27. Sturdza A, Pötter R, Fokdal LU et al. Image guided brachytherapy in locally advanced cervical cancer: Improved pelvic control and survival in RetroEMBRACE, a multicenter cohort study. Radiother Oncol 2016; 120: 428-433.

28. An International Study on Magnetic Resonance Imaging (MRI)-Guided Brachytherapy in Locally Advanced Cervical Cancer. Available at https://clinicaltrials.gov/ct2/show/ NCT00920920. Accessed February 15, 2019.

29. EMBRACE. Available at https://www.embracestudy.dk/ Public/Default.aspx?main $=2 \&$ sub $=16 \&$ embrace $=$ embrace 2 . Accessed February 26, 2019.

30. Charra-Brunaud C, Harter V, Delannes $M$ et al. Impact of 3D image-based PDR brachytherapy on outcome of patients treated for cervix carcinoma in France: Results of the French STIC prospective study. Radiother Oncol 2012; 103: 305-313.

31. Gill BS, Kim H, Houser CJ et al. MRI-guided high-dose-rate intracavitary brachytherapy for treatment of cervical cancer: the University of Pittsburgh experience. Int J Radiat Oncol Biol Phys 2015; 91: 540-547.

32. Haie-Meder C, Chargari C, Rey A et al. MRI-based low doserate brachytherapy experience in locally advanced cervical cancer patients initially treated by concomitant chemoradiotherapy. Radiother Oncol 2010; 96: 161-165.

33. Kang HC, Shin KH, Park S-Y et al. 3D CT-based high-doserate brachytherapy for cervical cancer: Clinical impact on late rectal bleeding and local control. Radiother Oncol 2010; 97: 507-513.

34. Lindegaard JC, Fokdal LU, Nielsen SK et al. MRI-guided adaptive radiotherapy in locally advanced cervical cancer from a Nordic perspective. Acta Oncologica 2013; 52: 15101519.

35. Narayan K, van Dyk S, Bernshaw D et al. Comparative study of LDR (Manchester system) and HDR image-guided conformal brachytherapy of cervical cancer: patterns of failure, late complications, and survival. Int J Radiat Oncol Biol Phys 2009; 74: 1529-1535.

36. Pötter R, Georg P, Dimopoulos JCA et al. Clinical outcome of protocol based image (MRI) guided adaptive brachytherapy combined with 3D conformal radiotherapy with or without chemotherapy in patients with locally advanced cervical cancer. Radiother Oncol 2011; 100: 116-123.

37. Rijkmans EC, Nout RA, Rutten IHHM et al. Improved survival of patients with cervical cancer treated with image-guided brachytherapy compared with conventional brachytherapy. Gynecol Oncol 2014; 135: 231-238.

38. Tan LT, Coles CE, Hart C et al. Clinical impact of computed tomography-based image-guided brachytherapy for cervix cancer using the tandem-ring applicator - the Addenbrooke's experience. Clin Oncol 2009; 21: 175-182. 